\title{
Journal of Photochemistry and Photobiology A: Chemistry
}

Invited feature article

\section{A bioinspired dye sensitized solar cell based on a rhodamine-functionalized peptide immobilized on nanocrystalline $\mathrm{TiO}_{2}$}

\author{
Mario Caruso ${ }^{\mathrm{a}}$, Emanuela Gatto $^{\mathrm{a}}$, Antonio Palleschi ${ }^{\mathrm{a}}$, Piero Morales ${ }^{\mathrm{b}}$, Manuela Scarselli ${ }^{\mathrm{c}}$, \\ Simone Casaluci ${ }^{\mathrm{d}}$, Alessia Quatela ${ }^{\mathrm{d}}$, Aldo Di Carlo ${ }^{\mathrm{d}}$, Mariano Venanzi ${ }^{\mathrm{a}, *}$ \\ a University of Rome Tor Vergata, Department of Chemical Sciences and Technologies, Via della Ricerca Scientifica 1, 00133 Rome, Italy \\ ${ }^{\mathrm{b}}$ ENEA,Casaccia Research Centre, Via Anguillarese 301, 00123 Santa Maria di Galeria, Rome, Italy \\ ${ }^{\mathrm{c}}$ University of Rome Tor Vergata, Department of Physics, Via della Ricerca Scientifica 1, 00133 Rome, Italy \\ ${ }^{\mathrm{d}}$ University of Rome Tor Vergata, Department of Electronics Engineering and CHOSE (Centre for Hybrid and Organic Solar Energy), Via del Politecnico 1, \\ 00133 Rome, Italy
}

\section{A R T I C L E I N F O}

\section{Article history:}

Received 19 May 2017

Received in revised form 12 July 2017

Accepted 13 July 2017

Available online 26 July 2017

\section{Keywords:}

Dye sensitized solar cell

Hybrid materials

Nanocrystalline $\mathrm{TiO}_{2}$

Peptide materials

Photocurrent generation

Rhodamine-based chromophore

\section{A B S T R A C T}

A dodecapeptide (AMRKLPDAPGMH) functionalized with a tetramethylrhodamine (TAMRA) chromophore at the N-terminus was immobilized on nanocrystalline $\mathrm{TiO}_{2}$. The optical and binding properties of the peptide layer immobilized on the titania surface were characterized by UV-vis absorption, steadystate fluorescence and X-ray photoelectron spectroscopies. Circular Dichroism experiments and Molecular Mechanics calculations showed that the predominant conformation populated by the peptide scaffold brings Arg3, Lys4 and Asp7 in the correct position for linking the $\mathrm{TiO}_{2}$ surface. Photocurrent generation experiments were therefore carried out to determine the photon-to-current conversion efficiency (IPCE) of a Grätzel-like Dye Sensitized Solar Cell (DSSC), the photoactive unit of which is formed by TAMRA-AMRKLPDAPGMH/ $\mathrm{TiO}_{2}$. The measured IPCE amounted to $0.65 \%$, a value that is definitely low, but superior to those previously reported for similar bioinspired DSSCs. This result can be ascribed to the light-harvesting properties of the TAMRA chromophore and to the unique structural properties of the peptide spacer.

(c) 2017 Elsevier B.V. All rights reserved.

\section{Introduction}

In the last decade, dye-sensitized solar cell (DSSC) technology has become a realistic alternative to classical silicon technology in solar energy conversion, because of its low cost, easy fabrication and reduced use of hazardous reagents during manufacturing [1].

DSSCs originated from the idea of mimicking photosynthesis, i.e. convert sunlight into electrical current by means of lightabsorbing dyes (analogously to the light-absorbing chlorophyll molecules in Nature) [2]. They are composed of a conducting glass coated by nanocrystalline titania, functionalized with a dye that, under illumination, injects electrons to $\mathrm{TiO}_{2}$, a semiconductor with a band gap of $3.2 \mathrm{eV}$. As in a conventional alkaline battery, the $\mathrm{TiO}_{2}$ surface works as the anode, while a platinum electrode usually accomplishes the role of the cathode. A suitable electrolytic

\footnotetext{
* Corresponding author.

E-mail address: venanzi@uniroma2.it (M. Venanzi).
}

solution is inserted between the two electrodes to allow electronic conduction.

Several groups have obtained $8-10 \%$ solar energy conversion efficiency using DSSC's based on nanocrystalline $\mathrm{TiO}_{2}[3,4]$. To increase the efficiency of the cell, different dye molecules [5], electrolytes [6], electron acceptors [7], co-sensitizers [8], absorber materials like perovskite [9] or different dye-titania linkers have been extensively tested [10].

In biological systems, electron transfer (ET) reactions efficiently occur along a sequential array of electron donor/acceptor moieties surrounded by a polypeptide matrix that is considered as a specialized ET mediator [11]. Helical secondary structures are the most frequently observed motifs in such polypeptide matrixes and are considered to play a crucial role in ET processes [12].

We have already demonstrated that peptide self-assembled monolayers (SAMs) represent the most suitable tool for modifying the surface properties of metallic substrates, paving the way to the realization of hybrid devices (soft meets hard) [13,14]. The introduction of SAMs, and in particular the identification of the 
thiol/Au route, has deeply transformed surface chemistry, opening a new pathway for preparing covalently linked thin films [15]. The great plasticity of SAMs brought about by the large choice of end groups that can be linked to the substrate, has greatly improved the number of applications in bio-inspired nanotechnology. Furthermore, it has been demonstrated that $\alpha$-helical peptides linked on semiconducting $\mathrm{TiO}_{2}$ are able to modify the electronic properties of the organic/solid interface, enhancing the charge-transfer efficiency of the system [16].

In this connection, a bio-inspired approach to DSSC technology, was recently developed in our laboratory making use of a helical peptide spacer, functionalized by a dye molecule and immobilized on $\mathrm{TiO}_{2}$ nanoparticles coated by a 5 nanometer-thick layer of gold [17].

In this work, we report on the photocurrent generation properties of a dodecapeptide functionalized with a rhodamine dye on a titania surface. Stable peptide films on $\mathrm{TiO}_{2}$ surfaces have already been obtained by using peptide chains with a specific binding sequence, namely the hexapeptide motif RKLPDA [18]. Interestingly, it has been found that the interaction of RKLPDA with $\mathrm{TiO}_{2}$ nanoparticles forced the hexapeptide to kink around the cis-P residue, directing $R$ and $D$ to the surface, so that the $R$ and $D$ side chains bound via electrostatic interaction to hydroxyl groups, that can act as either a basis $\left(\mathrm{Ti}-\mathrm{O}^{-}\right)$or acid $\left(\mathrm{Ti}-\mathrm{OH}_{2}{ }^{+}\right)$groups [19]. The choice of this specific, aqueous-soluble sequence, endowed with several potential anchoring groups, aimed to avoid the dye desorption in the organic solvent used in the photocurrent generation measurements, allowing for the realization of an efficient, long-life cell.

In this work, the RKLPDA motif was inserted between an Nterminal dipeptide, i.e. AM, and a C-terminal tetrapeptide, i.e. $\mathrm{PGMH}$, to form the dodecapeptide investigated. It should be noted that both the $\mathrm{N}$ - and $\mathrm{C}$-terminal end fragments predominantly comprise apolar amino acids. Furthermore, a 5-carboxytetramethylrhodamine (TAMRA) chromophore was covalently linked to the $\mathrm{N}$-terminus of the dodecapeptide, to act as a photosensitizer strongly absorbing in the visible region of the electromagnetic spectrum.

Xanthene dyes and their derivatives have been extensively used for biosensing applications, due to their low toxicity, high absorption coefficient, and high fluorescence quantum yield [20]. These properties make rhodamine-based chromophores promising candidates for applications where high sensitivity and resistance to photolysis are needed.

The molecular structure and acronym (T12) of the compound investigated are shown in Scheme 1.

\section{Materials and methods}

\subsection{Materials}

TAMRA-AMRKLPDAPGMH (T12) was synthesized by Eurogentech (Belgium) with a purity higher than 95\%. All solutions were prepared using spectroscopic grade solvents (Carlo Erba, Milan, Italy). Water was bi-distilled and de-ionized by passing through a Milli-Q purification system. Other chemicals have all reagent grade quality and were used without further purification. Other chemicals: HEPES (Sigma-Aldrich), sodium sulfate (SigmaAldrich), potassium chloride (Sigma-Aldrich).

\subsubsection{Preparation of $\mathrm{TiO}_{2} /$ Fluorine-doped tin oxide (FTO) substrates and $T 12$ film preparation}

Nanocrystalline titania layers were prepared by adsorbing screen printing Dyesol 18NR-T paste onto a transparent conductive glass substrate (Pilkington, TEC $8,8 \Omega /$ sq), followed by sintering at $480^{\circ} \mathrm{C}$ for $30 \mathrm{~min}$. The final film thickness, controlled by a Veeco Dektak 150 profilometer, was $6 \mu \mathrm{m}$. The size of the photoelectrode was $5 \times 5 \mathrm{~mm}^{2}$. After calcination, the photoelectrode was soaked in a $\mathrm{TiCl}_{4}$ aqueous solution [21].

For all experiments $\mathrm{TiO}_{2} /$ FTO substrates were washed with bidistilled water and ethanol before immersion in a millimolar peptide solution. Peptide-coated supports were prepared by dipping a clean substrate into a $2 \mathrm{mM}$ peptide HEPES buffer solution $(50 \mathrm{mM}, \mathrm{pH}=7)$. After $2 \mathrm{~h}$, the peptide-modified substrate was repeatedly rinsed with the buffer solution to remove physically adsorbed peptides and dried with a gentle flow of Argon.

\subsubsection{Preparation of a DSSC cell}

Transparent counter electrodes were prepared by firing a solution of Pt-paste (CHIMET) deposited by screen printing on a conductive glass for $15 \mathrm{~min}$ at $420^{\circ} \mathrm{C}$. These two electrodes were assembled by using a $60 \mu \mathrm{m}$-thick Surlyn gasket (Dupont 1702). The electrolyte solution was introduced by backfilling through a hole previously realized on the counter electrode.

\subsection{Methods}

\subsubsection{Spectroscopy and photoelectrochemistry}

All UV-vis absorption experiments were carried out at room temperature with a Cary 100 Scan spectrophotometer (Varian), using quartz cuvettes (Hellma) with optical lengths of 1, 0.5 and $0.1 \mathrm{~cm}$.

Circular dichroism (CD) spectra were recorded in HEPES buffer solution ( $\mathrm{pH} 7$ ) by a J-600 (Jasco) spectrometer, using a $0.1 \mathrm{~cm}$ quartz cuvette. Concentrations of peptide solutions were $10^{-5} \mathrm{M}$. Molar ellipticities are reported in terms of molar concentration per residue.

All steady-state fluorescence measurements were carried out on a SPEX Fluoromax-4 (HORIBA, Jobin Yvon) spectrofluorimeter using Single Photon Counting (SPC) acquisition mode. All spectra in solution were recorded by using quartz cuvettes with an optical length of $1 \mathrm{~cm}$. All the fluorescence experiments were carried out on solutions showing absorbance less than 0.03 to minimize innerfilter effect. Fluorescence spectra of peptide films supported on $\mathrm{TiO}_{2} /$ FTO substrates were recorded in transmittance mode on a

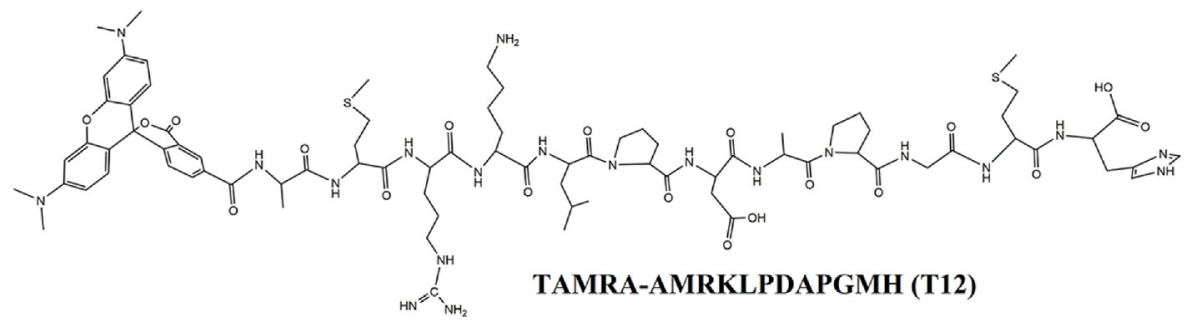

Scheme 1. Molecular formula and acronym of the peptide investigated. 
support oriented at an angle of $30^{\circ}$ with respect to the excitation beam direction.

Fluorescence time decays were recorded using a LifeSpec instrument (Edinburgh Analytical Instruments) equipped with a multi-channel analyzer (MCA). The excitation source was a $460 \mathrm{~nm}$ diode laser. The full width at half maximum (FWHM) of the excitation pulse was $1 \mathrm{~ns}$. Experimental time decays were fitted by non-linear least square analysis through iterative reconvolution of a multiexponential trial function with the experimental excitation source profile.

X-ray Photoelectron Spectroscopy (XPS) measurements were recorded with a semi-imaging analyzer MAC 2 (Riber Instruments) operating in the constant pass energy mode. A non-monochromatized $\mathrm{Al} \mathrm{K \alpha}(1486.6 \mathrm{eV})$ radiation source $(9 \mathrm{kV}, 700 \mathrm{~W})$ was used. The distance between the sample and the anode was about $40 \mathrm{~mm}$; the illumination area was about $5 \times 5 \mathrm{~mm}^{2}$, while the take-off angle between the sample surface and the photoelectron energy analyzer was kept at $45^{\circ}$. The energy scale was calibrated with reference to the binding energy of the $\mathrm{Ti} 2 \mathrm{p} 3 / 2$ signal of $\mathrm{TiO}_{2}$ having a binding energy $\mathrm{BE}=458.7 \mathrm{eV}$. Curve fitting analysis of the $\mathrm{C} 1 \mathrm{~s}$, $\mathrm{N} 1 \mathrm{~s}$ and $\mathrm{O} 1 \mathrm{~s}$ spectra was done using a standard Gaussian curve fit routine with Shirley background subtraction. The quality of the fit was evaluated by using $\chi^{2}$ minimization test.

Photocurrent generation experiments were carried out using a Xenon lamp light source equipped with a monochromator (band pass $15 \mathrm{~nm}$ ); the power density of the incident light was evaluated by a power meter. A PG-310 potentiostat was used as a current detector. The electrochemical cell adopted a standard threeelectrode configuration. The electrolyte solution was $0.01 \mathrm{M} \mathrm{I}_{2}$, $0.5 \mathrm{M} \mathrm{KI}$ in acetonitrile. Electronic current vs. applied voltage (I-V) spectra were carried out with a Keithley 2420 Source. I-V curves were measured under an air mass (AM) 1.5G solar simulator (Solar Constant from KHS) at 1 Sun lighting.

\subsubsection{Conformational analysis of T12}

Molecular Mechanics (MM) calculations were carried out by using the MM4 force field, where solvents effects are only implicitly taken into account [22]. The MM4 results were validated by using the AM1 and PM3 semiempirical methods [23]. Initial conformations were generated assuming a statistical population of folded and extended helical peptide structures by using standard bond lengths and bond angles for all residues. The Pro6 and Pro8 residues were initially assumed to adopt a polyproline type II conformation. The conformational energy was therefore optimized by taking into account electrostatic, non-bonding, hydrogen bond and torsional interactions. Stretching and bending motions, as implemented in the MM4 force field were also taken into account.

\section{Results and discussion}

\subsection{Optical spectroscopy and conformational analysis in solution}

The UV-vis absorption and fluorescence spectra of T12 in HEPES buffer solution $(\mathrm{pH}=7)$ are both reported in Fig. 1 . The former shows the typical, broad $\pi \rightarrow \pi^{*}$ absorption band of rhodamine B featuring an intense absorption peak at $\lambda_{\max }=550 \mathrm{~nm}$ [24]. From the figure, it can be easily seen that the $S_{1} \rightarrow S_{0}$ emission band, peaked at $\lambda_{\max }=572 \mathrm{~nm}$, almost mirrors the $\pi \rightarrow \pi^{*}$ absorption band.

Time resolved fluorescence measurements provided a single lifetime of $2.4 \mathrm{~ns}$ for all the T12 solutions investigated (1-50 $\mu \mathrm{M})$, a value similar to the reported lifetime of cationic rhodamine B [25].

The conformational properties of T12 in a HEPES buffer solution ( $\mathrm{pH} 7)$ were investigated by Circular Dichroism measurements (Fig. 2). The deep minimum observed at around $205 \mathrm{~nm}\left(\mathrm{n} \rightarrow \pi^{*}\right.$ transition), suggests that T12 attains a statistical population of

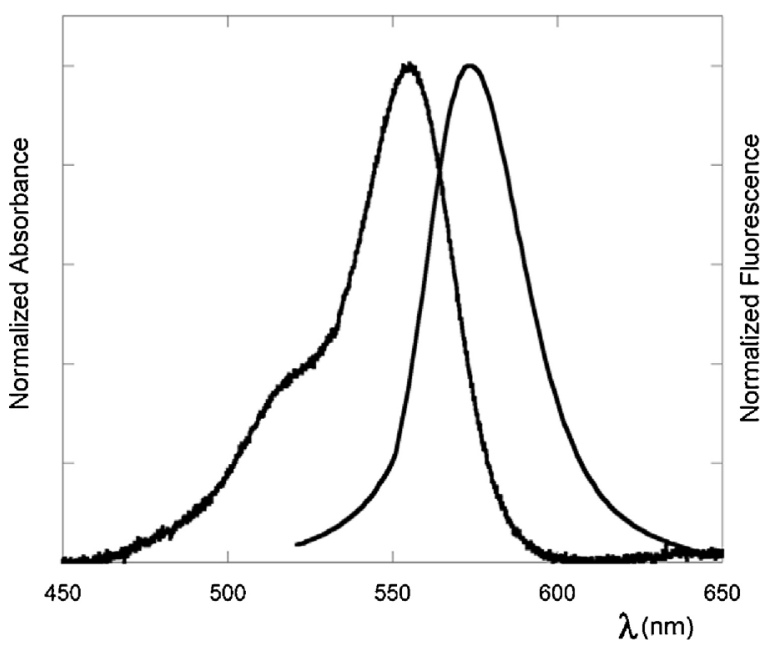

Fig. 1. Absorption and fluorescence emission spectrum of T12 in a HEPES buffer solution $(\mathrm{pH}=7)$ at $1 \mu \mathrm{M}$ concentration.

conformers with a predominant contribution of polyproline type II-like conformation [26]. The latter is a left-handed helix $\left(\phi=-75^{\circ} ; \chi=146^{\circ} ; \omega=180^{\circ}\right)$ with 3 residues per turn and a $3.1 \AA$ A rise per residue, characterized by a predominant extended structure [27]. For this unique property, oligoprolines have traditionally been used as molecular spacers in FRET studies, although the rigidity of such spectroscopic rulers has been recently questioned [28].

Molecular Mechanics (MM, AM1, PM3) calculations were carried out to analyze the conformational preferences of T12, focusing on two specific issues: i) the localization of groups, i.e. peptide side-chains, potentially capable of linking to the $\mathrm{TiO}_{2}$ surface, and ii) the localization of the TAMRA chromophore and its potential interaction with the surface and/or with other rhodamine groups.

The most stable conformer provided by MM calculations is reported in Fig. 3. It was found that the presence of Pro9 strengthens the propensity of the RKLPDA motif to preferentially adopt an extended conformation mimicking polyproline type II, in agreement with $C D$ results. A very similar $W$-shaped structure was recently found by Suzuki et al. [29], investigating the binding of RKLPDA to $\mathrm{TiO}_{2}$ nanoparticles by NMR experiments. In particular,

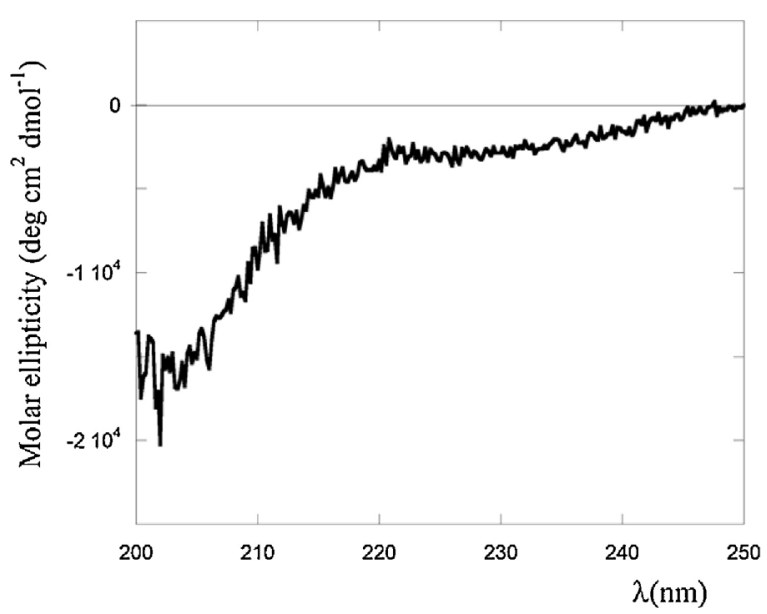

Fig. 2. Circular dichroism spectrum of $\mathbf{T 1 2}$ in HEPES buffer solution ( $\mathrm{pH} 7$ ) at $1 \mu \mathrm{M}$ concentration. 


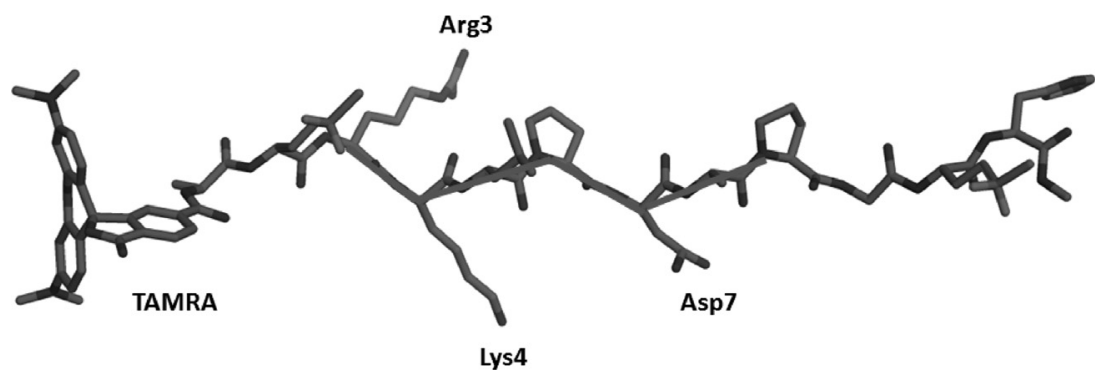

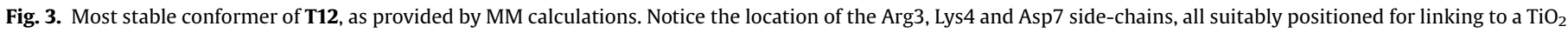
surface. The orange segment emphasizes the rigid, W-like skeleton of the dodecapeptide investigated.

they found that $\operatorname{Arg} 1$ and Lys2, through their N-terminal groups, were principally responsible for anchoring the peptide to the $\mathrm{TiO}_{2}$ surface. However, they also found that the C-terminal segment of the peptide is rather flexible.

In our case, the presence of Pro9 confers some extra-rigidity to the C-terminal end of T12. Furthermore, we found that, besides Arg3 and Lys4, also Asp7 is suitably positioned to bind to positively-charged group $\left(-\mathrm{OH}_{2}^{+}\right)$on the $\mathrm{TiO}_{2}$ surface. Regarding the localization of TAMRA, MM calculations suggest that it could be held in the proximity of the $\mathrm{TiO}_{2}$ surface by the Arg3 and Lys4 anchoring groups. Due to the relative rigidity of the peptide scaffold, the T12 low-energy conformers are essentially characterized by a different orientation of the TAMRA chromophore. Considering Arg3, Lys4 and Asp7 in the proper position for binding to the $\mathbf{T i O}_{2}$ surface, the minimum distance from TAMRA to the surface amounts to $3.5 \AA$, while the most stable conformer shows a minimum distance from $\mathrm{TiO}_{2}$ of about $5 \AA$.

This orientationally restricted location and the presence of the sterically hindered $\mathrm{N}$-methyl groups on the TAMRA scaffold, most likely would inhibit short-range rhodamine-rhodamine interactions and block the chromophore in a position in the proximity of the conductive surface, but avoiding the overlap between the TAMRA electronic states and the surface density of states of $\mathrm{TiO}_{2}$.

\subsection{Optical and X-ray photoelectron spectroscopy of T12 adsorbed on $\mathrm{TiO}_{2}$}

Interestingly, after deposition on the titania substrate, T12 film shows a marked blue shift of the $\pi \rightarrow \pi^{*}$ absorption band $\left(\lambda_{\max }=530 \mathrm{~nm}\right.$, Fig. 4A), and a rather intense fluorescence emission spectrum (Fig. 4B), quite similar to the monomer emission (Fig. 2). These results strongly suggest, in agreement with the computational results, that TAMRA is not interacting with the manifold of the semiconductor surface states, otherwise his fluorescence should be almost totally quenched. The fact that the TAMRA emission retains the shape of the monomer emission, also strongly suggests that TAMRA-TAMRA interactions are negligible. Self-association in solution or at the solid/liquid interface is a frequently encountered phenomenon in dye chemistry, owing to attractive van der Waals interactions between the aromatic moieties. The resulting aggregates exhibit distinct changes in the absorption band as compared to the monomeric species, depending on the aggregation geometry [30]. For example, H-type aggregates are characterized by a sandwich-like configuration of the aromatic moieties, giving rise to hypsochromically-shifted absorption bands. In this case, the symmetry-allowed transition involves the electronic ground state and the high energy excitonic state [31], with a consequent shift of the absorption band to the blue side of the spectrum. In this type of aggregates, the relaxation to the ground state is very fast and generally occurs between excitonic states with vanishing dipole transition moments. As a result, most of the excitation energy is dissipated through nonradiative pathways, and $\mathrm{H}$ aggregates usually show a very low fluorescence.

In summary, optical spectroscopy results indicate that TAMRA is not undergoing fluorescence quenching interactions with the $\mathrm{TiO}_{2}$ surface, and that it is not involved in H-type stacking interactions with nearby TAMRA moieties, as well.

These findings suggest that TAMRA is positioned near the $\mathrm{TiO}_{2}$ surface, allowing for efficient electron transfer, but at a sufficiently large distance to avoid overlapping between the chromophore and the semiconductor surface electronic states. This situation would promote efficient through-space electron transfer, inhibiting charge recombination or relaxation through energy dissipation.
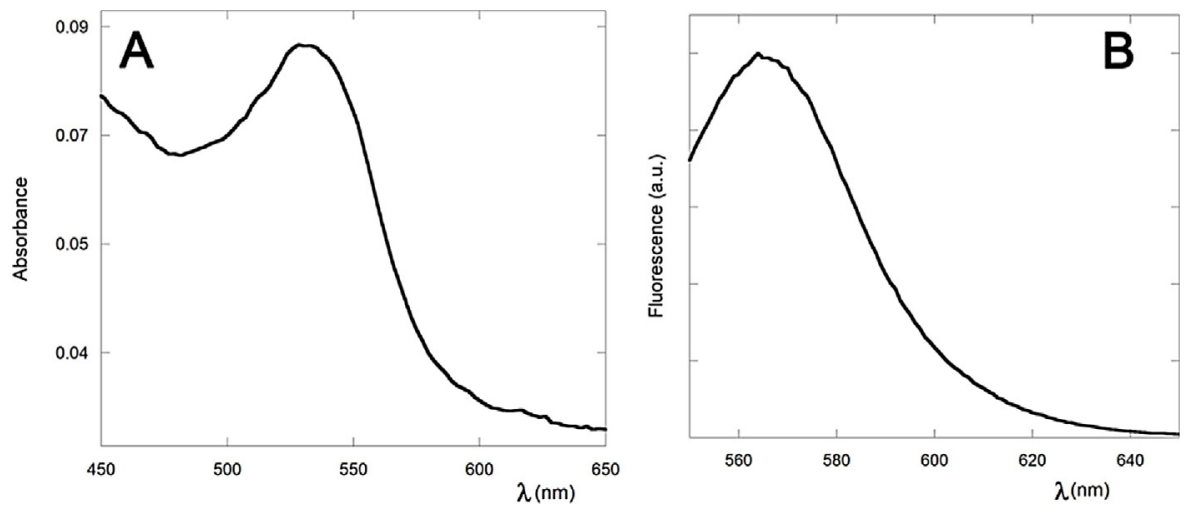

Fig. 4. UV-vis absorption (A) and fluorescence emission spectrum (B) of T12 supported on $\mathrm{TiO}_{2}$. 

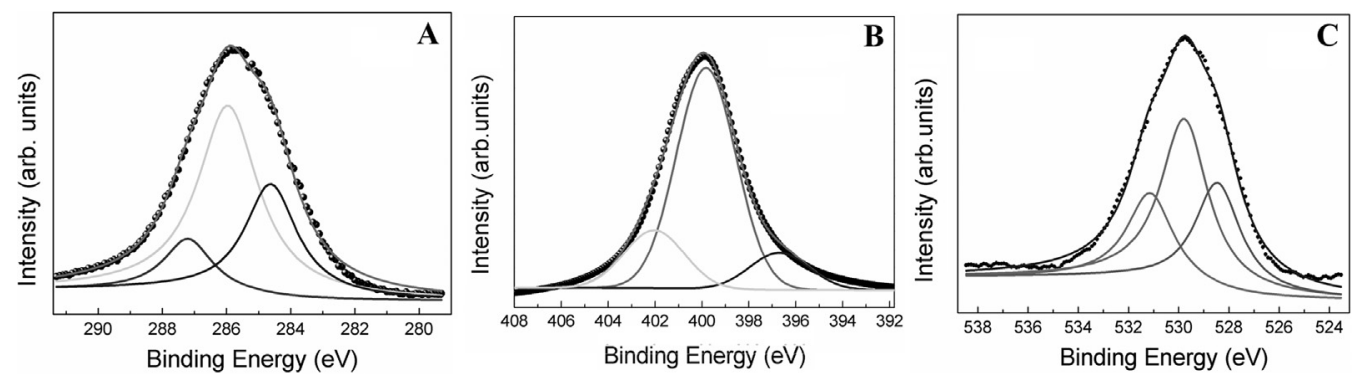

Fig. 5. X-ray photoelectron spectra of $\mathbf{T 1 2}$ on $\mathrm{TiO}_{2}$. A: C 1s; B: $\mathrm{N} 1 \mathrm{~s} ; \mathrm{C}$ : O $1 \mathrm{~s}$.

It may be questioned about the contribution of through-bond pathways to the ET efficiency. From the calculations we obtained that the TAMRA distance from the surface ranges between 3.5 and $5 \AA$, while the through bond distance considering the first linkage through the anchoring nitrogen atoms of the Arg3 side-chain is $19.8 \AA$. The dependence of ET rate constant on the donor-acceptor distance can be described through the equation:

$k_{E T}=k_{0} e^{-\beta \cdot R_{D A}}$

In a theoretical work, Shin et al. [32], showed that in the case of the polyproline type II conformation $\beta=0.7 \AA^{-1}$. Assuming $\beta=1.1 \AA^{-1}$ for through-space ET $\left(R_{D A}=5 \AA\right)$, this means that through-space ET should be favored with respect to through-bond $\left(R_{D A}=19.8 \AA\right)$ ET by a factor larger than $4 \cdot 10^{3}$.

$\mathrm{X}$-ray Photoelectron Spectroscopy (XPS) measurements were carried out to characterize the $\mathbf{T 1 2} \cdots \mathrm{TiO}_{2}$ binding interaction. Extended XPS surveys of the $\mathrm{TiO}_{2}$ surface carried out before and after peptide deposition reveal a marked attenuation of the $\mathrm{Ti}$ contribution coming from the substrate (Fig. S1, Supporting information), suggesting the formation of a thick T12 layer. Furthermore, upon T12 linkage, evidences of some oxidation processes can be obtained by the decrease of the Ti 2p3/2 lines in the range $455-470 \mathrm{eV}$, attributed to $\mathrm{Ti}$ ions in the lower oxidation states [33].

Fig. 5 shows the contributions from the $\mathrm{C}, \mathrm{N}$ and $\mathrm{O}$ elements composing the peptide film and the associated curve-fittings after adsorption on $\mathrm{TiO}_{2}$.

The $\mathrm{C} 1 \mathrm{~s}$ core level spectrum consists of three components (Fig. 5A), one located at $284.6 \mathrm{eV}$, assigned to carbon atoms involved in $\mathrm{C}-\mathrm{C} / \mathrm{C}-\mathrm{H}$ bonds, a second one at $286 \mathrm{eV}(\mathrm{C}-\mathrm{OH}$ groups), that is the main contribution to the signal, and a third signal at $287.2 \mathrm{eV}$ that originates from the $\mathrm{C}=\mathrm{O}$ groups.

In the N1s XPS spectrum three different $\mathrm{N}$ components can be observed (Fig. 5B): one at $402 \mathrm{eV}$, that can be assigned to $\mathrm{H}_{\mathrm{x}}^{+} \mathrm{N}$ species, a second one at $399.8 \mathrm{eV}\left(\mathrm{H}_{2} \mathrm{~N}-\right)$ [34], and a minor contribution at $396.7 \mathrm{eV}$, that most likely originates from Ti-N contacts formed during the film deposition [35], respectively.

The 01s spectrum (Fig. 5C) also features three components, one ascribable to the $\mathrm{TiO}_{2}$ substrate $(529.4 \mathrm{eV})$, the second one to carbonyl $\mathrm{O}$ groups on the surface $(532 \mathrm{eV})$ and the third one to the surface hydroxyl groups formed during the dissociative adsorption reaction (530.4 eV), respectively [36].

The results of the curve fitting procedure for all relevant XPS signals are summarized in Table 1.

\subsection{Photoelectrochemical experiments}

Photocurrent generation (PG) experiments were carried out on a $\mathrm{TiO}_{2} /$ FTO electrode modified by adsorption of a T12 peptide film. Interestingly, a very high anodic current was generated upon illumination in the visible region of the $\mathbf{T 1 2} / \mathrm{TiO}_{2} / \mathrm{FTO}$ modified electrode in the presence of the $\mathrm{I}^{-} / \mathrm{I}_{3}{ }^{-}$redox pair in solution.

Fig. 6A shows repeated light-on/light-off cycles carried out for different excitation wavelengths.

When the peptide layer is irradiated in the range comprised between 470 and $600 \mathrm{~nm}$, T12 gives rise to an electron transfer process from its excited state to the conduction band of $\mathrm{TiO}_{2}$ (Fig. 6B). After that, the $\mathrm{I}^{-} / \mathrm{I}_{3}{ }^{-}$redox pair in solution transfers an electron to the oxidized TAMRA, producing a net, anodic electronic current.

As $\mathrm{TiO}_{2}$ absorbs light only in the UV-range, the excitation bandgap being $3.2 \mathrm{eV}$, the strong photocurrent signal measured in the visible region can be safely ascribed to the TAMRA dye functionalizing the peptide. This is confirmed by the photocurrent action spectrum, i.e. the excitation wavelength dependence of the photocurrent response of the $\mathbf{T 1 2} / \mathrm{TiO}_{2} /$ FTO electrode, shown in Fig. 7. The latter strictly overlaps the absorption spectrum of T12, indicating that TAMRA is responsible for triggering the photoinduced electron transfer process.

The incident photon to current efficiency (IPCE) of the $\mathbf{T 1 2} / \mathrm{TiO}_{2} /$ FTO photoactive unit can be evaluated through the equation:

$\operatorname{IPCE}(\%)=100 \cdot \frac{i\left(\mathrm{~A} / \mathrm{cm}^{2}\right) \cdot 1240}{I\left(\mathrm{~W} / \mathrm{cm}^{2}\right) \cdot \lambda}$

where $\mathrm{i}$ is the photocurrent density $\left(\mathrm{A} / \mathrm{cm}^{2}\right)$, $\mathrm{I}$ is the incident power density $\left(\mathrm{W} / \mathrm{cm}^{2}\right)$ and $\lambda$ is the incident photon-wavelength (nm). The IPCE value at $\lambda_{\text {exc }}=550 \mathrm{~nm}$ and under null bias potential is $0.55 \pm 0.05 \%$. This promising result urged us to investigate the

Table 1

X-rays Photoelectron Spectroscopy energies of $\mathbf{T 1 2}$ on $\mathrm{TiO}_{2}$.

\begin{tabular}{|c|c|c|c|c|c|}
\hline Element & Binding Energy $(\mathrm{eV})$ & Signal emitters & Element & Binding Energy $(\mathrm{eV})$ & Signal emitters \\
\hline \multirow[t]{3}{*}{ C $1 \mathrm{~s}$} & 284.6 & $\mathrm{C}-\mathrm{C} / \mathrm{C}-\mathrm{H}$ & $01 \mathrm{~s}$ & 529.4 & $\mathrm{TiO}_{2}$ \\
\hline & 286.0 & $\mathrm{C}-\mathrm{OH}$ & & 530.4 & $\mathrm{Ti}-\mathrm{OH}$ \\
\hline & 287.2 & $\mathrm{C}=\mathrm{O}$ & & 532.0 & $\mathrm{C}-\mathrm{O}$ \\
\hline \multirow[t]{3}{*}{$\mathrm{N} 1 \mathrm{~s}$} & 399.8 & $\mathrm{NH}_{2}$ & & & \\
\hline & 402.0 & $\mathrm{NH}_{3}^{+}$ & $\operatorname{Ti} 2 \mathrm{p}$ & 459.0 & $\mathrm{TiO}_{2}$ \\
\hline & & & & 464.5 & $\mathrm{TiO}_{2}$ \\
\hline
\end{tabular}




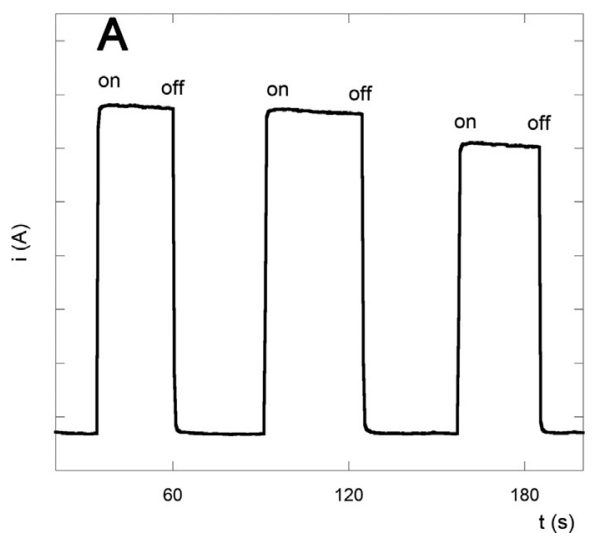

B

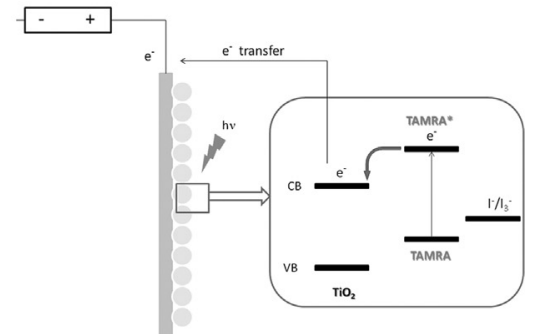

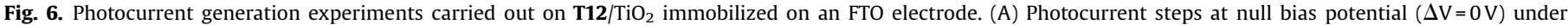

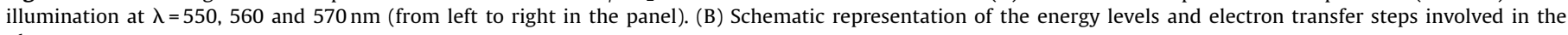
photocurrent process.

possibility of using T12 for building a prototype Dye Sensitized Solar Cell (DSSC).

\subsection{Construction of a $\mathrm{T12} / \mathrm{TiO}_{2}$ dye sensitized solar cell}

Bio-inspired DSSC's using photosynthetic proteins for the design of new-concept devices for photoelectric conversion have been already realized [37-39]. Unfortunately the low stability of natural proteins once extracted from their biological environment, severely limits their use.

Peptides have been shown to feature unique electron transfer properties, in terms of superior ET efficiency over very long distances, ET asymmetry and robustness over many photoinduced ET cycles [40]. In this connection, we recently reported on PG experiments carried out using a gold electrode modified by a SAM

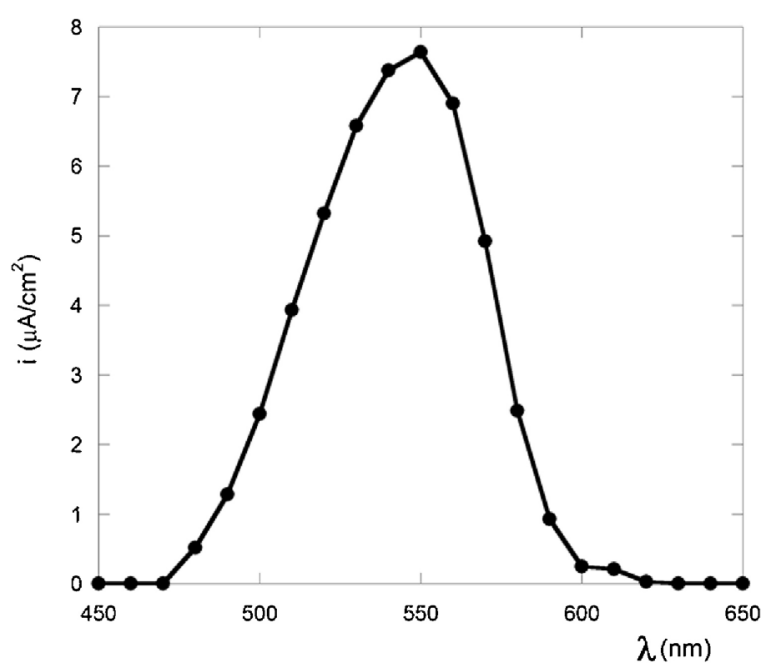

Fig. 7. Photocurrent action spectrum of the $\mathrm{T} 12 / \mathrm{TiO}_{2} / \mathrm{FTO}$ electrode, showing the excitation wavelength dependence of the photocurrent intensity.

Table 2

Operative parameters of the T12 based DSSC.

\begin{tabular}{lllll}
\hline Sample & $\mathrm{V}_{\mathrm{oc}}(\mathrm{V})$ & $\mathrm{J}_{\mathrm{sc}}\left(\mathrm{mA} / \mathrm{cm}^{2}\right)$ & Efficiency $(\%)$ & Fill Factor \\
\hline $\mathrm{T12}_{\mathrm{TiO}}$ & $0.45( \pm 0.05)$ & $2.3( \pm 0.1)$ & $0.65( \pm 0.05)$ & $66 \%$ \\
$\mathrm{TiO}_{2}$ & $0.50( \pm 0.1)$ & $0.9( \pm 0.1)$ & $0.29( \pm 0.1)$ & $64 \%$ \\
\hline
\end{tabular}

formed by a helical thiolated peptide [41]. At that time, we were able to show that a helical peptide scaffold suitably functionalized with an antenna chromophore could enhance light-induced electron-hole separation (antenna effect).

Following the same approach, we built a prototype DSSC using a $\mathrm{TiO}_{2} /$ FTO electrode coated with a T12 film as a working electrode and an FTO conducting glass coated with platinum as a counter electrode. The latter was placed directly on the top of the working electrode, using a Surlyn film. PG experiments carried out with this cell showed high stability after several cycles of measurements and an efficiency of $0.65 \pm 0.05 \%$ under simulated solar light illumination, definitely higher than the efficiencies measured in a DSSC using rhodamine as the photoactive element [42] or natural dye extracts $[43,44]$.

In particular, the photovoltaic performance of Rhodamine B was already investigated by Choopun et al. using $\mathrm{ZnO}$ as the conductive substrate [45]. In that case, they obtained an efficiency of $0.18 \%$, more than 3 times lower than that one measured by us for the T12/ $\mathrm{TiO}_{2}$ system.

This is most likely due to the increased energy gap between the LUMO energy of the dye and the conduction band of the metal oxide (Fig. 6B), enhancing the charge transfer rate constant and therefore, the photoconversion efficiency [46]. The operative parameters of the T12-based DSSC, reported as the average of the results obtained during four days-long experiments, are reported in Table 2, in comparison with the analogous DSSC using bare $\mathrm{TiO}_{2}$ nanoparticles as a working electrode.

The voltages measured under open circuit conditions (Voc's) using a $\mathrm{TiO}_{2}$ /FTO electrode with or without the peptide layer, are almost the same. This finding indicates that the peptide layer does not affect the efficiency of charge recombination, contrasting with what found for vertically-arranged self-assembled monolayers formed by $31_{10}$-helical peptide building blocks [41]. In that case, charge recombination is inhibited by the electrostatic field associated to the peptide helix dipole, that preferentially promotes ET from the $\mathrm{C}$ - to the $\mathrm{N}$-terminus. As suggested by $\mathrm{CD}$ experiments and MM calculations, T12 attains a polyproline type II conformation that was shown to contribute almost negligibly to the stabilization of charge-transfer states, due to the weak electrostatic field associated to peptide backbone attaining this specific conformation [32]. Besides that, in analogy with what we have recently found for a peptide film horizontally layered on a gold surface by two side-chain dithiol groups [14], the topology of the $\mathrm{T} 12 / \mathrm{TiO}_{2}$ integrated system, strongly favors trough-space ET, limiting the role of the peptide chain as a rigid scaffold holding 


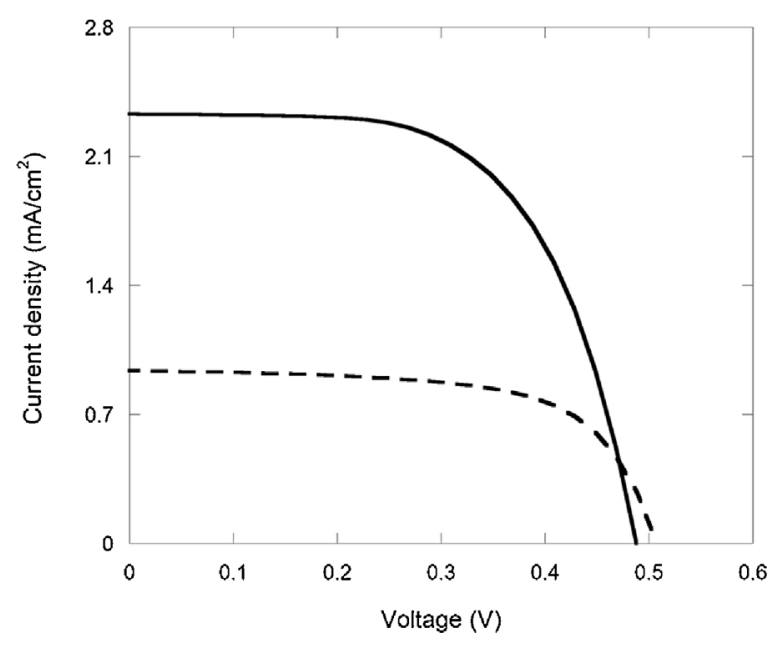

Fig. 8. Current density vs voltage response of the $\mathrm{T12} / \mathrm{TiO}_{2} / \mathrm{FTO}$ electrode (continuous line) and of the bare $\mathrm{TiO}_{2} /$ FTO electrode (dotted line).

the TAMRA chromophore in the most convenient position for efficient ET. On the other hand, the presence of several anchoring groups contributes to prevent aggregation, but limits the coverage of $\mathrm{TiO}_{2}$, diminishing light harvest.

Interestingly, T12-based DSSC shows definitely higher shortcircuit density currents $\left(\mathrm{J}_{\mathrm{sc}}\right)$, i.e. the current that flows through the external circuit when the electrodes of the solar cell are short circuited. This parameter therefore represents the maximum current that can be delivered by a solar cell, and is directly related to the generation and collection of light-generated electron/hole carriers.

This finding is further emphasized by the data shown in Fig. 8, where the current-voltage $(\mathrm{I} / \mathrm{V})$ dependence, obtained with the T12/ $/ \mathrm{TiO}_{2} /$ FTO thin layer cell under an air mass (AM) $1.5 \mathrm{G}$ solar simulator at 1 Sun lighting, was reported in comparison with the photoresponse of a bare $\mathrm{TiO}_{2} /$ FTO electrode.

From the data reported in Fig. 8, it can be easily seen that the current density at all applied voltages is definitely larger for the T12 $/ \mathrm{TiO}_{2} /$ FTO-coated electrode, the current-density limit at short circuit $\left(\mathrm{J}_{\mathrm{sc}}\right)$ being 3-times larger than the one measured for the bare $\mathrm{TiO}_{2} /$ FTO electrode. This result emphasizes the role of the peptide scaffold as a rigid spacer, preventing charge-recombination for structural reasons, due to the electronic properties of the polyproline type II conformation attained by the peptide chain $[27,28,32]$, and the topology of the $\mathrm{T} 12 / \mathrm{TiO}_{2}$ film, characterized by the presence of multiple side-chain linkers, that constrain the peptide chain to attain a relatively rigid location horizontally layered with respect to the $\mathrm{TiO}_{2}$ surface.

\section{Conclusions}

The formation of a stable peptide film on $\mathrm{TiO}_{2}$ and its ability to generate an electronic current under continuous electromagnetic excitation were clearly demonstrated. The peptide investigated comprised a core sequence (RKLPDA) well-known to be able to specifically bind $\mathrm{TiO}_{2}$ by means of several side-chain groups, i.e. the arginine and lysine protonated amines and the aspartic carboxylate groups. The role of the peptide is to held the TAMRA chromophore in the most convenient position for efficient ET and to modulate the electronic properties of the $\mathrm{TiO}_{2}$ surface. In particular, the peptide layer, acting as a rigid scaffold, avoids that the photoexcited rhodamine chromophores would dissipate their excitation energy by mixing to the manifold of the $\mathrm{TiO}_{2}$ electronic states.

Our results indicate that peptide scaffolds can be considered promising materials for the development of molecular components to be used in DSSCs. We demonstrate that a T12-based DSSC shows an efficiency of $0.65 \%$, which is awfully low if compared with the efficiency of silicon-based solar cells, but superior to previously reported studies on similar bio-inspired systems.

In any case, the evidence that photosensitizers embedded in a peptide matrix give rise to a current density definitely higher than bare $\mathrm{TiO}_{2}$ materials, is, in our opinion, of relevant interest. This is, to the best of our knowledge, the first example of a peptide-based DSSC, where the peptide is directly linked to the $\mathrm{TiO}_{2}$ surface.

The key advantages of using peptides in bioelectronics are their well-defined molecular structure, facile molecular design and arrangement of functional groups along the molecule, unique templating and self-organizing properties, and stability after several cycles of measurements.

Furthermore, at the end of life of the dye and/or of the peptide, the cell can be easily regenerated by reduction of the peptidemetal bond and incubation of the electrode in a peptide solution.

A specific result of this work is the possibility to finely tuning the electronic properties of the metal or semiconductor electrodes by covalent deposition of vertically or horizontally layered peptide films. In the former case, helically arranged peptide layers can assume an active role, favoring directional ET from the C- to the Nterminus, while in the latter is predominant the structural role of the peptide chain as a conformationally well-defined spacer.

We do hope that the results presented here will prompt new efforts to improve the efficiency of peptide-based DSSC, optimizing the parameters that determine the photocurrent generation efficiency, from the harvest of photoexcitation by a suitable molecular antenna to the cell current production.

\section{Notes}

The authors declare no competing financial interest.

\section{Aknowledgements}

This work was supported by the Italian Ministry of University and Research (MIUR), PRIN 2010-2011 No. 2010FM738P, 'Photophysical and photochemical properties of organic and biological compounds in solution and in organized systems' and by European Union IRSES scheme META project.

\section{Appendix A. Supplementary data}

Supplementary data associated with this article can be found, in the online version, at http://dx.doi.org/10.1016/j. jphotochem.2017.07.027.

\section{References}

[1] J.-S. Hwang, C.-Y. Wu, Y.-H. Tai, P. Tseng, S. Chattopadhyay, Y.-C. Chiu, S.-W. Chen, Making silicon solar cells in a green, low-hazardous, and inexpensive way, RSC Adv. 5 (2015) 9425-9431.

[2] A. Hagfeldt, G. Boschloo, L. Sun, L. Kloo, H. Pettersson, Dye-sensitized solar cells, Chem. Rev. 110 (2010) 6595-6663.

[3] S. Ito, T.N. Murakami, P. Comte, P. Liska, C. Grätzel, M.K. Nazeeruddin, M. Grätzel, Fabrication of thin film dye- sensitized solar cells with solar to electric power conversion efficiency over 10\%, Thin Solid Films 516 (2008) 4613-4619.

[4] S.-Q. Fan, C. Kim, B. Fang, K.-X. Liao, G.-J. Yang, C.-J. Li, J.-J. Kim, J. Ko, Improved Efficiency of over $10 \%$ in dye-sensitized solar cells with a ruthenium complex and an organic dye heterogeneously positioning on a single $\mathrm{TiO}_{2}$ electrode, J. Phys. Chem. C 115 (2011) 7747-7754.

[5] M. Mao, X.-L. Zhang, X.-Q. Fang, G.-H. Wu, S.-Y. Dai, Q.-H. Song, X.-X. Zhang, Highly efficient light-harvesting boradiazaindacene sensitizers for dye- 
sensitized solar cells featuring phenothiazine donor antenna, J. Power Sources 268 (2014) 965-976.

[6] A. Latini, F.K. Aldibaja, C. Cavallo, D. Gozzi, Benzonitrile based electrolytes for best operation of dye-sensitized solar cells, J. Power Sources 269 (2014) 308316.

[7] H. Zhu, W. Li, Y. Wu, B. Liu, S. Zhu, X. Li, H. Ågren, W. Zhu, Insight into benzothiadiazole acceptor in $\mathrm{D}-\mathrm{A}-\pi-\mathrm{A}$ configuration on photovoltaic performances of dye-sensitized solar cells, ACS Sustain. Chem. Eng. 2 (2014) 1026-1034.

[8] L. Yu, K. Fan, T. Duan, X. Chen, R. Li, T. Peng, Efficient panchromatic light harvesting with co-sensitization of zinc phthalocyanine and bithiophenebased organic dye for dye-sensitized solar cells, ACS Sustain. Chem. Eng. 2 (2014) 718-725.

[9] N.-G. Park, Organometal perovskite light absorbers toward a 20\% efficiency low-cost solid-state mesoscopic solar cell, J. Phys. Chem. Lett. 4 (2013) 24232429.

[10] Z. Wan, C. Jia, Y. Duan, L. Zhou, Y. Lin, Y. Shi, Phenothiazine-triphenylamine based organic dyes containing various conjugated linkers for efficient dyesensitized solar cells, J. Mater. Chem. 22 (2012) 25140.

[11] M. Cordes, B. Giese, Electron transfer in peptides and proteins, Chem. Soc. Rev. 38 (2009) 892-901.

[12] M. Venanzi, E. Gatto, M. Caruso, A. Porchetta, F. Formaggio, C. Toniolo Photoinduced electron transfer through peptide-based self-assembled monolayers chemisorbed on gold electrodes: directing the flow-in and flowout of electrons through peptide helices, J. Phys. Chem. A 118 (2014) 66746684.

[13] E. Gatto, M. Venanzi, Self-assembled monolayers formed by helical peptide building blocks: a new tool for bioinspired nanotechnology, Polym. J. 45 (2013) 468-480.

[14] E. Longo, K. Wright, M. Caruso, E. Gatto, A. Palleschi, M. Scarselli, M. De Crescenzi, M. Crisma, F. Formaggio, C. Toniolo, M. Venanzi, Peptide flatlandia: a new concept peptide for positioning of electroactive probes in proximity to a metal surface, Nanoscale 7 (2015) 15495-15506.

[15] J.C. Love, L.A. Estroff, J.K. Kriebel, R.G. Nuzzo, G.M. Whiteside, Self-assembled monolayers of thiolates on metals as a form of nanotechnology, Chem. Rev. 105 (2005) 1103-1170.

[16] P. Tarakeshwar, J.L. Palma, G.P. Holland, P. Fromme, J.L. Yarger, V. Mujica, Probing the nature of charge transfer at nano-bio interfaces: peptides on metal oxide nanoparticles, J. Phys. Chem. Lett. 5 (2014) 3555-3559.

[17] E. Gatto, A. Quatela, M. Caruso, R. Tagliaferro, M. De Zotti, F. Formaggio, C. Toniolo, A. Di Carlo, M. Venanzi, M. Mimicking Nature, A novel peptide-based bio-inspired approach for solar energy conversion, ChemPhysChem 15 (2014) 64-68.

[18] K.-I. Sano, K. Shiba, A hexapeptide motif that electrostatically binds to the surface of titanium, J. Am. Chem. Soc. 125 (2003) 14234-14235.

[19] K.-I. Sano, H. Sasaki, K. Shiba, Specificity and biomineralization activities of Tibinding peptide-1 (TBP-1), Langmuir 21 (2005) 3090-3095.

[20] P.K. Baviskar, J.B. Zhang, V. Gupta, S. Chand, B.R. Sankapal, Nanobeads of zinc oxide with rhodamine B dye as a sensitizer for dye-sensitized solar cell application, J. Alloys Compd. 510 (2012) 33-37.

[21] L. Vesce, R. Riccitelli, G. Soscia, T.M. Brown, A. Di Carlo, A. Reale, Optimization of nanostructured titania photoanodes for dye-sensitized solar cells: study and experimentation of $\mathrm{TiCl}_{4}$ treatment, J. Non Cryst. Solids 356 (2010) 1958-1961.

[22] B. Pispisa, A. Palleschi, L. Stella, M. Venanzi, C. Toniolo, A nitroxide derivative as a probe for conformational studies of short linear peptides in solution. spectroscopic and molecular mechanics investigation, J. Phys. Chem. B 102 (1998) 7890-7898.

[23] M. Froimowitz, HyperChem: a software package for computational chemistry and molecular modeling, BioTechniques 14 (1993) 1010-1013.

[24] J.A.B. Ferreira, S.M.B. Costa, Rhodamine $3 \mathrm{~B}+\mathrm{ClO}_{4}^{-}$electronic transitions: reaction field and vibrational structure, Chem. Phys. 273 (2001) 39-49.

[25] M. Beija, C.A.M. Afonso, J.M.G. Martinho, Synthesis and applications of Rhodamine derivatives as fluorescent probes, Chem. Soc. Rev. 38 (2009) 2410 2433.

[26] R.W. Woody, Optical rotatory properties of polypeptides, J. Polym. Sci.: Macromol. Rev. 181 (1977) 181-309.
[27] M. Moradi, V. Babin, C. Roland, T.A. Darden, C. Sagui, Conformations and free energy landscapes of polyproline peptides, Proc. Natl. Acad. Sci. U. S. A. 109 (2009) 20746-20751.

[28] S. Doose, H. Neuweiler, H. Barsh, M. Sauer, Probing polyproline structure and dynamics by photoinduced electron transfer provides evidence for deviations from a regular polyproline type II helix, Proc. Natl. Acad. Sci. U. S. A. 104 (2007) $17400-17405$

[29] Y. Suzuki, H. Shindo, T. Asakura, Structure and dynamic properties of a Tibinding peptide bound to $\mathrm{TiO}_{2}$ nanoparticles as accessed by $1 \mathrm{H}$ NMR spectroscopy, J. Phys. Chem. B 120 (2016) 4600-4607.

[30] M. Caruso, E. Placidi, E. Gatto, C. Mazzuca, L. Stella, G. Bocchinfuso, A. Palleschi, F. Formaggio, C. Toniolo, M. Venanzi, Fibrils or globules? Tuning the morphology of peptide aggregates from helical building blocks, J. Phys. Chem B 117 (2013) 5448-5459.

[31] G. de Miguel, M. Ziółek, M. Zitnan, J.A. Organero, S.S. Pandey, S. Hayase, A. Douhal, Photophysics of $\mathrm{H}$ - and J-aggregates of indole-based squaraines in solid state, J. Phys. Chem. C 116 (2012) 9379-9389.

[32] J.K. Shin, M.D. Newton, S.S. Isied, Distance dependence of electron transfer across peptides with different secondary structures: the role of peptide energetics and electronic coupling, J. Am. Chem. Soc. 125 (2003) 3722-3732.

[33] M. Okada, P. Jin, Y. Yamada, M. Tazawa, K. Yoshimura, Low-energy electron energy loss spectroscopy of rutile and anatase $\mathrm{TiO}_{2}$ films in the core electron excitation regions, Surf. Sci. 566-568 (2004) 1030-1034.

[34] G.J. Fleming, K. Adib, J.A. Rodriguez, M.A. Barteau, H. Idriss, Proline adsorption on $\mathrm{TiO}_{2}(110)$ single crystal surface: a study by high resolution photoelectron spectroscopy, Surf. Sci. 601 (2007) 5726-5731.

[35] K.L. Syres, A.G. Thomas, D.M. Graham, B.F. Spencer, W.R. Flavell, M.J. Jackman, V.R. Dhanak, Adsorption and stability of malonic acid on rutile $\mathrm{TiO}_{2}(110)$ studied by near edge X-ray absorption fine structure and photoelectron spectroscopy, Surf. Sci. 626 (2014) 14-20.

[36] J. Singh, A. Gusain, V. Saxena, A.K. Chauhan, P. Veerender, S.P. Koiry, P. Jha, A. Jain, D.K. Aswal, S.K. Gupta, X.P.S. UV-Vis, FTIR, and EXAFS studies to investigate the binding mechanism of N719 dye onto oxalic acid treated $\mathrm{TiO}_{2}$ and its implication on photovoltaic properties, J. Phys. Chem. C 117 (2013) 21096-21104.

[37] O. Yehezkeli, R. Tel-Vered, J. Wasserman, A. Trifonov, D. Michaeli, R. Nechushtai, I. Willner, Integrated photosystem II-based photobioelectrochemical cells, Nat. Commun. 3 (2012) 742.

[38] A. Onoda, Y. Kakikura, T. Uematsu, S. Kuwabata, T. Hayashi, Photocurrent generation from hierarchical zinc-substituted hemoprotein assemblies immobilized on a gold electrode, Angew. Chem. Int. Ed. 51 (2012) 2628-2631.

[39] L. Tsui, J. Huang, M. Sabat, G. Zangari, Visible light sensitization of TiO nanotubes by bacteriochlorophyll-C dyes for photoelectrochemical solar cells, ACS Sustain. Chem. Eng. 2 (2014) 2097-2101.

[40] E. Gatto, M. Venanzi, Peptronics Peptide materials for electron transfer, in: C. Aleman, A. Bianco, M. Venanzi (Eds.), Peptide Materials: from Nanostructures to Applications, Wiley, Chichester, UK, 2013, pp. 105-147 and references therein.

[41] E. Gatto, M. Caruso, A. Porchetta, C. Toniolo, F. Formaggio, M. Crisma, M Venanzi, Photocurrent generation through peptide-based self-assembled monolayers on a gold surface: antenna and junction effects, J. Pept. Sci. 17 (2011) 124-131.

[42] H. Setyawati, H. Darmokoesoemo, F. Rochman, A.J. Permana, Promising dyesensitizer on solar cell from complexes of metal and rhodamine B, Int. J. Renew. Energy Res. 16 (2015) 694-698.

[43] H. Chang, H.M. Wu, T.L. Chen, K.D. Huang, C.S. Jwo, Y.J. Lo, Dye-sensitized solar cell using natural dyes extracted from spinach and ipomoea, J. Alloys Compd. 495 (2010) 606-610.

[44] H. Zhou, L. Wu, Y. Gao, T. Ma, Dye-sensitized solar cells using 20 natural dyes as sensitizers, J. Photochem. Photobiol. A Chem. 219 (2011) 188-194.

[45] P. Ruankham, C. Sae-kung, N. Mangkorntong, P. Mangkorntong, S. Choopun, Photoelectrochemical characteristic of ZnO dye-sensitized solar cell with platinum nanoparticle as a counterelectrode, CMU J. Nat. Sci. 7 (2008) 177-183 Special Issue on Nanotechnology.

[46] P. Tarakeshwar, D. Finkelstein-Shapiro, S.J. Hurst, T. Rajh, V. Mujica, Surfaceenhanced Raman scattering on semiconducting oxide nanoparticles: oxide nature, size, solvent, and pH effects, J. Phys. Chem. C 115 (2011) 8994-9004. 